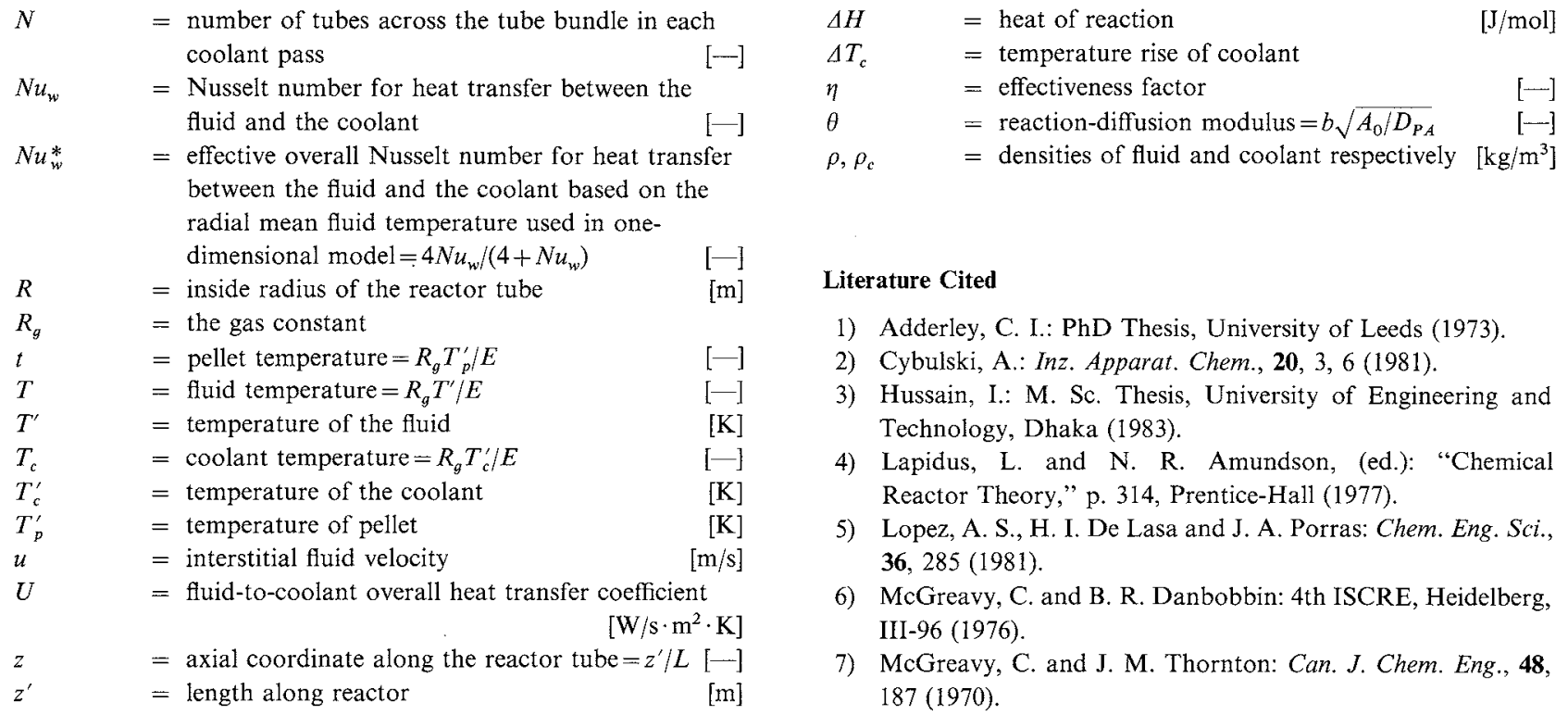

\title{
KINETICS OF CARBON DEPOSITION ON NICKEL METAL BY DECOMPOSITION OF CARBON MONOXIDE
}

\author{
NoBoru SAKAI, TADASHI CHIDA, TEIRIKI TADAKI \\ AND JUNZO SHIMOIIZAKA \\ Department of Mining and Mineral Engineering, Tohoku University, Sendai 980
}

Key Words: Chemical Reaction, Carbon Deposition, Adsorption, Carbon Monoxide, Nickel

\begin{abstract}
The kinetics of carbon deposition are reported for the temperature range $773-1023 \mathrm{~K}$. A reaction model composed of adsorption and reaction steps is proposed and compared with experimental data. In this model the rate equation of carbon deposition takes into account the catalytic action of nickel. The calculated results are in good agreement with the experimental ones. The activation energy and the heat of adsorption of $\mathrm{CO}$ are $59.3 \mathrm{~kJ} / \mathrm{mol}$ and $61.7 \mathrm{~kJ} / \mathrm{mol}$, respectively.
\end{abstract}

\section{Introduction}

Reduction of a metal oxide with $\mathrm{CO}$ is accompanied under certain conditions by the decomposition of carbon monoxide according to the reaction $2 \mathrm{CO}=$ $\mathrm{C}+\mathrm{CO}_{2}{ }^{6,11)}$ The presence of deposited carbon interferes with the gas flow and diffusion within a reactor, and therefore affects the reduction of the metal oxide. Thus, information concerning the mechanism and rate of carbon deposition is required in order to analyze the overall reduction process. Carbon deposition on metallic iron has been reported $^{5,9,13)}$ when reduction of iron oxide occurred

Received June 27, 1984. Correspondence concerning this article should be addressed to N. Sakai. T. Tadaki is at Dept. of Chem. Eng., Tohoku Univ., Sendai 980. with $\mathrm{CO}$, and some rate equations have been obtained for this case. Taniguchi et al. ${ }^{12)}$ proposed a rate equation in which the catalytic action of iron carbide was taken into account. Further, Knapp et $a l^{4)}$ proposed a Langmuir-Hinshelwood type equation for carbon deposition in the rate of magnetite reduction with carbon monoxide.

For nickel oxide, however, the equations mentioned above are not useful for estimating the reaction rate because nickel carbide is unstable at temperatures above $673 \mathrm{~K} .{ }^{1)}$ Carbon deposition on nickel catalyst has been studied in relation with catalyst deactivation, ${ }^{3,7,10)}$ but a rate equation has not been obtained. In this study, experiments of carbon deposition catalyzed by nickel are carried out and a 


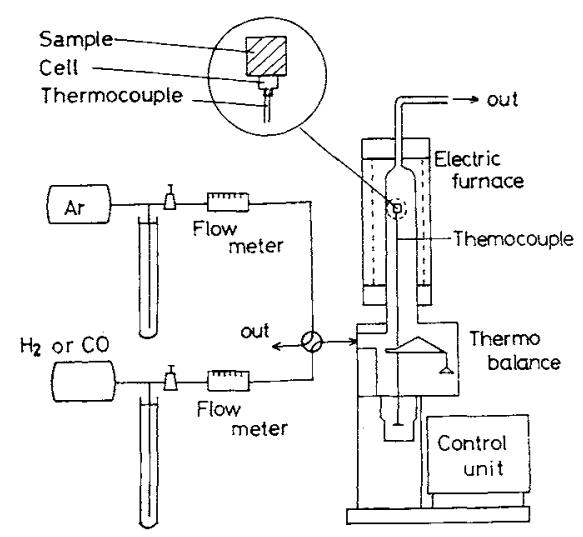

Fig. 1. Schematic diagram of experimental apparatus.

reaction model is proposed. In the model, the rate equation of carbon deposition on nickel is assumed to be influenced by the catalytic action of reduced nickel.

The mechanism which gives the maximum rate of carbon deposition at about $773 \mathrm{~K}^{5,12)}$ has not been understood very well. However, the model proposed in this study gives a possible explanation.

\section{Experimental}

Nickel oxide used in this study was pure $\mathrm{NiO}$ powder with an average diameter, measured with a microscope, of $6.5 \mu \mathrm{m}$. A solid sample was prepared as follows. About $200 \mathrm{mg}$ of $\mathrm{NiO}$ powder was spread on a thin Ni plate $(0.1 \mathrm{~mm} \times 1 \mathrm{~cm} \times 1 \mathrm{~cm})$ to make a thin layer of the oxide, so that the maximum thickness of the layer could be less than $1 \mathrm{~mm}$. The experimental apparatus is sketched in Fig. 1. The sample was placed in a cell, perpendicular to the gas flow in a reaction tube, and it was reduced by $\mathrm{H}_{2}$ at the temperature at which carbon deposition occurred; then the reactant, $\mathrm{CO}$ or $\mathrm{CO}-\mathrm{Ar}$ mixture was introduced into the reaction tube. The rate of carbon deposition was essentially independent of gas flow rate employed $\left(1.0 \times 10^{-3} \mathrm{~m}^{3}\right.$ (N.T.P.)/min). The weight change of the sample was obtained with an automatic recording thermogravimetric unit. Reaction temperature was measured with a thermocouple placed near the sample as shown in Fig. 1, and was controlled by a P.I.D. control unit.

\section{Experimental Results}

Figure 2 shows the effect of the weight of $\mathrm{NiO}$ powder on the carbon deposition rate at $973 \mathrm{~K}$. In this figure, experimental results are represented in the form

$$
W=w / w_{\mathrm{Ni}}
$$

where $w$ and $w_{\mathrm{Ni}}$ are the weight change of sample and the weight of nickel metal reduced from $\mathrm{NiO}$ with $\mathrm{H}_{2}$, respectively. It can be seen from this figure that the deposition rate is independent of the $\mathrm{NiO}$ weight, that

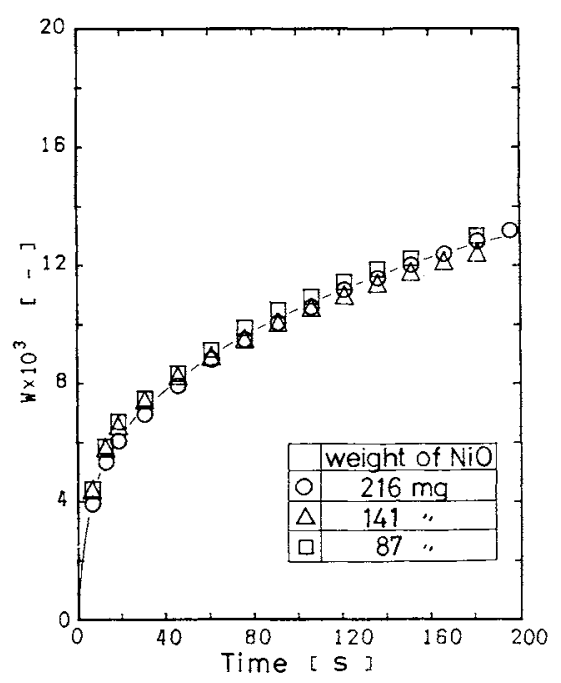

Fig. 2. Effect of $\mathrm{NiO}$ weight on reaction rate at $973 \mathrm{~K}$.

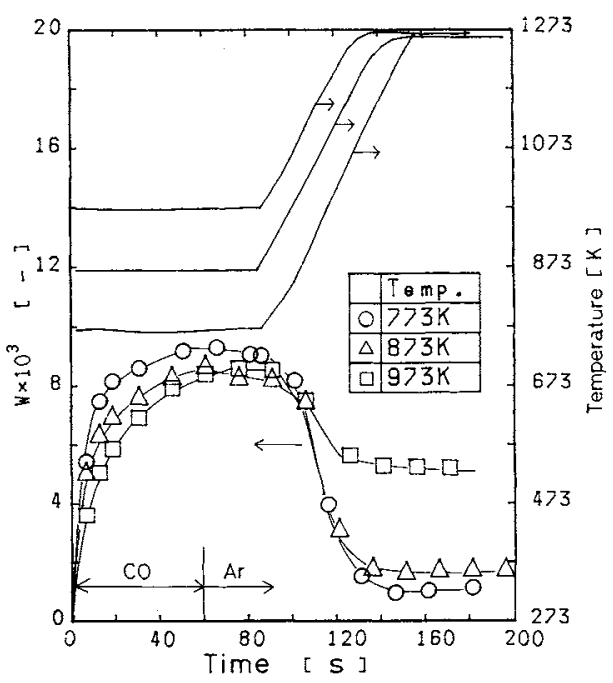

Fig. 3. Effect of adsorption on reaction rate.

is, the thickness of the sample, so that the effects of the existence of the Ni plate and the resistance of gas diffusion within the sample layer on the overall rate can be neglected. Since it is inferred that an adsorption step affects the overall reaction rate, ${ }^{8)}$ the following experiments were carried out. $\mathrm{CO}$ gas was introduced for one minute at a reaction temperature ranging from 773 to $973 \mathrm{~K}$, and was thereafter replaced by Ar gas. After 30 seconds the temperature was rapidly raised to $1273 \mathrm{~K}$. The results are shown in Fig. 3. The weight change $W$ increases rapidly in about the first 30 seconds (initial reaction stage). $W$ decreases slowly in an atmosphere of $\mathrm{Ar}$ gas. However, it decreases rapidly to a constant value when the temperature is elevated to $1273 \mathrm{~K}$. The final value of $W$ at $973 \mathrm{~K}$ is higher than that at $773 \mathrm{~K}$. It is revealed by this fact that the weight increase is mainly attributable to adsorption of $\mathrm{CO}$ at the initial stage of the reaction, and that in the range of $773-973 \mathrm{~K}$ the amount of deposited carbon increases with rising 


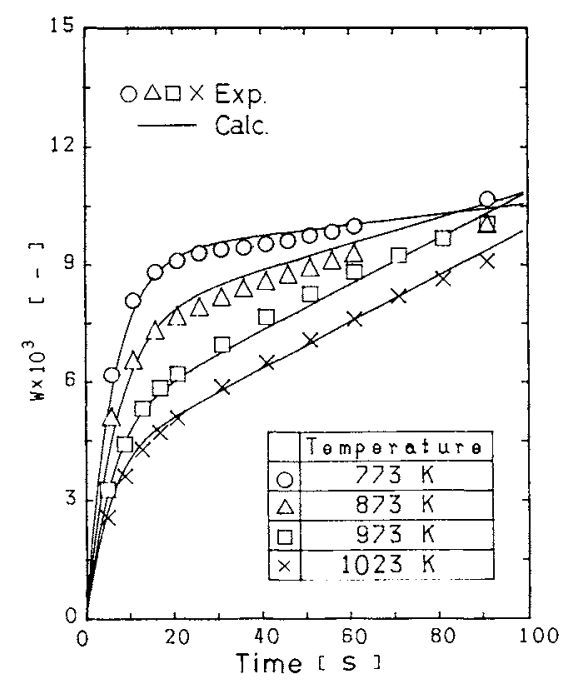

Fig. 4. Carbon deposition at various temperatures and $\mathrm{CO}$ atmospheric pressure.

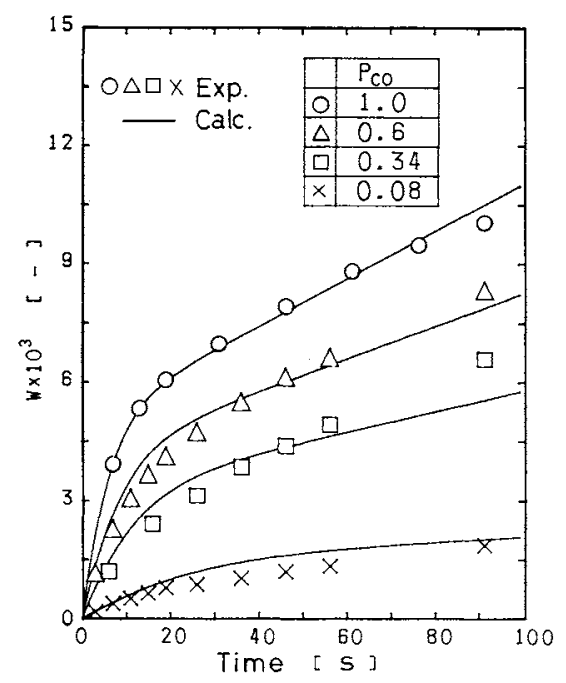

Fig. 5. Carbon deposition at various CO partial pressures and $973 \mathrm{~K}$.

\section{reaction temperature.}

Figure 4 shows the effect of reaction temperature on the carbon deposition rate. The reaction is fast at the initial stage, and gradually slows down to an almost constant value. It can also be seen from this figure that the lower the temperature is the higher the reaction rate at the initial stage. After about 30 seconds the rate increases with increasing temperature. These facts are in accordance with the experimental results reported by Turkdogan and coworkers. ${ }^{13)}$ That is, they reported that in the early stages of reaction the rate is highest at about $803 \mathrm{~K}$ and in the later stages of carbon deposition a maximum rate is obtained at about $1073 \mathrm{~K}$.

Figure 5 shows carbon deposition at various $\mathrm{CO}$ partial pressures. The initial reaction rate depends on the CO partial pressure, but after 30 seconds its effect becomes small. In a logarithmic plot, shown in Fig. 6,

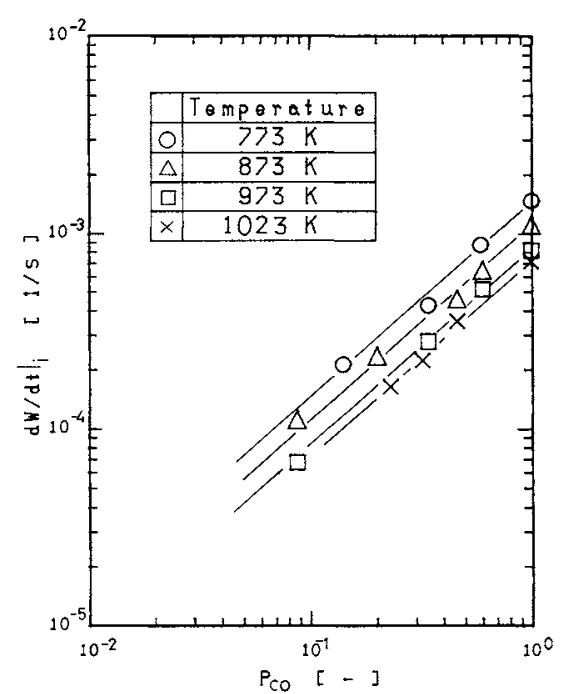

Fig. 6. $d W / d t_{i}$ vs. $P_{\mathrm{CO}}$.

the relation between the initial rate, $d W /\left.d t\right|_{i}$, and the partial pressure of $\mathrm{CO}, P_{\mathrm{CO}}$, is essentially linear. The initial rate was calculated from the data by the numerical differential method. The slopes of lines in Fig. 6 are almost unity.

\section{Discussion}

\subsection{Determination of the rate equation for carbon deposition}

The following two overall reactions can be considered.

$$
\begin{gathered}
2 \mathrm{CO}=\mathrm{C}+\mathrm{CO}_{2} \\
2 \mathrm{CO}+3 \mathrm{Ni}=\mathrm{Ni}_{3} \mathrm{C}+\mathrm{CO}_{2}
\end{gathered}
$$

However, reaction (2) can be ignored because nickel carbide is unstable above $673 \mathrm{~K}^{11}$

The reaction process will involve the adsorption of $\mathrm{CO}$ on the surface of solid to form a surface complex $\mathrm{CO}^{*}$. Two $\mathrm{CO}^{*}$ may transform to carbon and a surface complex $\mathrm{CO}_{2}^{*}$, which then desorbs to give a gaseous product $\mathrm{CO}_{2}$. These steps, which are reversible in general, may be written as

$$
\begin{gathered}
\mathrm{CO}+\sigma \rightleftharpoons \mathrm{CO}^{*} \\
2 \mathrm{CO}^{*} \rightleftharpoons \mathrm{C}+\mathrm{CO}_{2}^{*}+\sigma \\
\mathrm{CO}_{2}^{*} \rightleftharpoons \mathrm{CO}_{2}+\sigma
\end{gathered}
$$

where $\sigma$ designates an active adsorption site that is available to both $\mathrm{CO}$ and $\mathrm{CO}_{2}$.

Assume the following restrictions in order to make the mathematical formulation tractable.

(1) The reaction takes place under isothermal conditions.

(2) Deposited carbon does not decrease the number of active adsorption sites.

(3) Desorption of $\mathrm{CO}_{2}$ is so rapid that its effect on the overall reaction rate is negligible. 
(4) The reverse reaction of Eq. (4) can be ignored when the bulk concentration of $\mathrm{CO}_{2}$ is almost zero.

(5) Gas diffusion in the external gas film and intraparticle diffusion do not affect the overall reaction rate.

Then, the change of $\mathrm{CO}^{*}$ concentration with time, $d S_{\mathrm{Co}} / d t$, can be given by the following equation.

$$
\frac{d S_{\mathrm{CO}}}{d t}=k_{1} C_{\mathrm{CO}}\left(S_{\mathrm{t}}-S_{\mathrm{CO}}\right)-k_{1}^{\prime} S_{\mathrm{CO}}-2 k_{2} S_{\mathrm{CO}}^{2}
$$

where $k_{1}$ and $k_{1}^{\prime}$ are $\mathrm{CO}$ adsorption and desorption rate constants, respectively, and $k_{2}$ is the reaction rate constant of Eq. (4).

The rate of weight change is expressed by Eq. (7):

$$
\frac{d W}{d t}=M_{\mathrm{CO}} \frac{d S_{\mathrm{CO}}}{d t}+M_{\mathrm{C}} k_{2} S_{\mathrm{CO}}^{2}
$$

Initial conditions are as follows:

$$
\text { At } t=0 \quad S_{\mathrm{CO}}=0, W=0
$$

Equations (6)-(8) can be rewritten in dimensionless form as

$$
\begin{aligned}
& \frac{d \theta}{d \tau}=1-\left(1+P_{1}\right) \theta-P_{2} \theta^{2} \\
& \frac{d X}{d \tau}=\frac{d \theta}{d \tau}+\frac{P_{2}}{2} \frac{M_{\mathrm{C}}}{M_{\mathrm{CO}}} \theta^{2} \\
& \text { I.C. } \quad \tau=0 ; \quad \theta=0, \quad X=0
\end{aligned}
$$

where

$$
\begin{aligned}
& \theta=S_{\mathrm{CO}} / S_{\mathrm{t}}, \quad P_{1}=1 / K_{\mathrm{e}} C_{\mathrm{CO}}, \\
& P_{2}=2 k_{2} S_{\mathrm{t}} / k_{1} C_{\mathrm{CO}}, \quad \tau=k_{1} C_{\mathrm{CO}} t, \\
& X=W / S_{\mathrm{t}} M_{\mathrm{CO}}, \quad K_{\mathrm{e}}=k_{1} / k_{1}^{\prime}
\end{aligned}
$$

Using the Runge-Kutta-Gill method, the dimensionless weight $X$ can be calculated. However, the values of the parameters $S_{\mathrm{t}}, k_{1}, k_{1}^{\prime}\left(\right.$ or $k_{\mathrm{e}}$ ) and $k_{2}$ are necessary in order to calculate $X$.

\subsection{Estimation of parameters}

1) Estimation of $S_{t}$ If the desorption rate of $\mathrm{CO}$ and the rate of reaction (4) are small enough compared with the adsorption rate of CO, Eq. (6) can be expressed as

$$
\frac{d S_{\mathrm{Co}}}{d t}=k_{1} C_{\mathrm{Co}}\left(S_{\mathrm{t}}-S_{\mathrm{Co}}\right)
$$

At the reaction temperature of $773 \mathrm{~K}$, it should be noted from the weight change between 60 and $90 \mathrm{sec}-$ onds in Fig. 3 that the desorption rate of $\mathrm{CO}$ is small enough. It should be also seen from the weight change after 30 seconds in Fig. 4 that reaction (4) scarcely takes place. Then the weight increase can be attributed to $\mathrm{CO}$ adsorption at the initial stage at $773 \mathrm{~K}$ and $W=M_{\mathrm{CO}} S_{\mathrm{CO}}$. Figure 7 shows the relation between

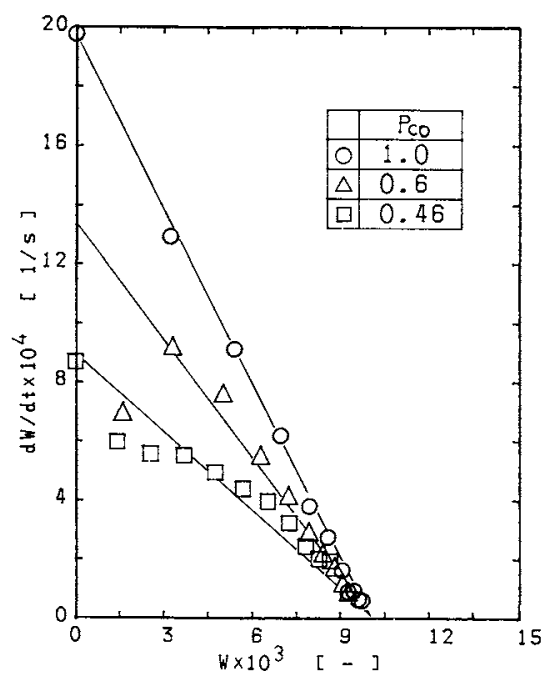

Fig. 7. $d W / d t$ vs. $W$ at $773 \mathrm{~K}$.

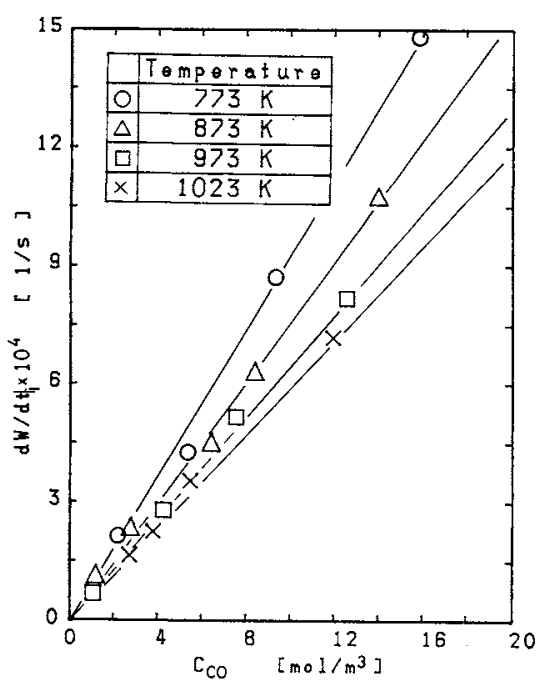

Fig. 8. $d W / d t_{i}$ vs. $C_{\mathrm{CO}}$.

$d W / d t$ and $W$ at the initial stage at $773 \mathrm{~K}$. The values of $d W / d t$ in this figure are calculated from the data by the numerical differentiation method. The relation is almost linear. From the intersection between the lines and the abscissa, $S_{\mathrm{t}}$ is evaluated according to Eq. (13):

$$
S_{\mathrm{t}}=\left.\left(W / M_{\mathrm{CO}}\right)\right|_{d W / d t=0}=3.6 \times 10^{-4} \quad[\mathrm{~mol} / \mathrm{g}]
$$

2) Estimation of $k_{1}$ At the initial state, $S_{\mathrm{CO}}$ can be assumed to be zero, and then the adsorption rate is proportional to concentration of $\mathrm{CO}$ as given by Eq. (14).

$$
\frac{d S_{\mathrm{CO}}}{d t}=k_{1} C_{\mathrm{CO}} S_{\mathrm{t}}
$$

The relation between the initial rate and the concentration of $\mathrm{CO}$ is shown in Fig. 8. It can be seen from this figure that the relation is almost linear. Figure 9 shows the adsorption rate constant calculated from the slope of lines in Fig. 8. The dependence of $k_{1}$ on the temperature is small. 


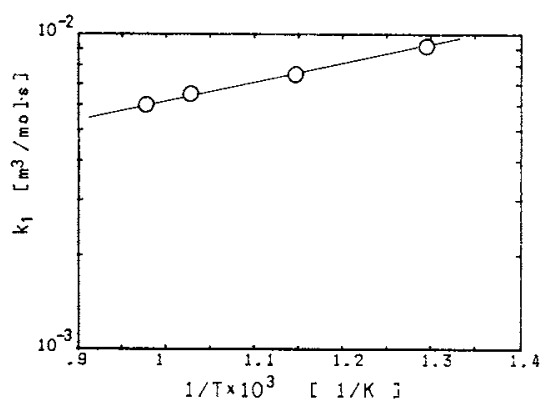

Fig. 9. Arrhenius plot of $k_{1}$.

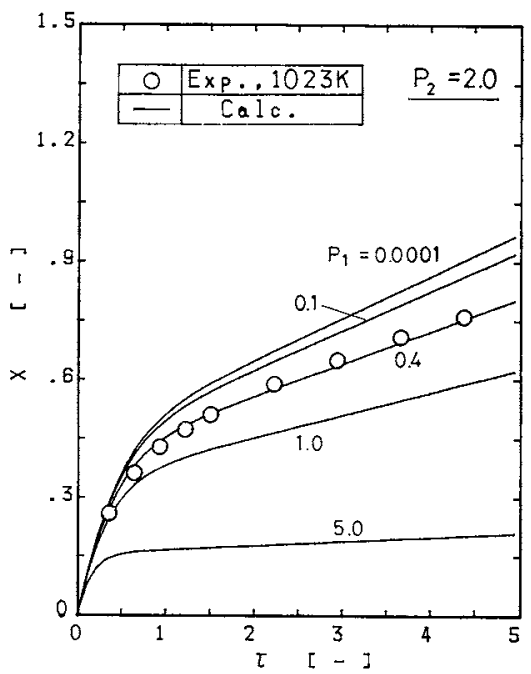

Fig. 10. Effect of $P_{1}$ on calculated reaction rate.

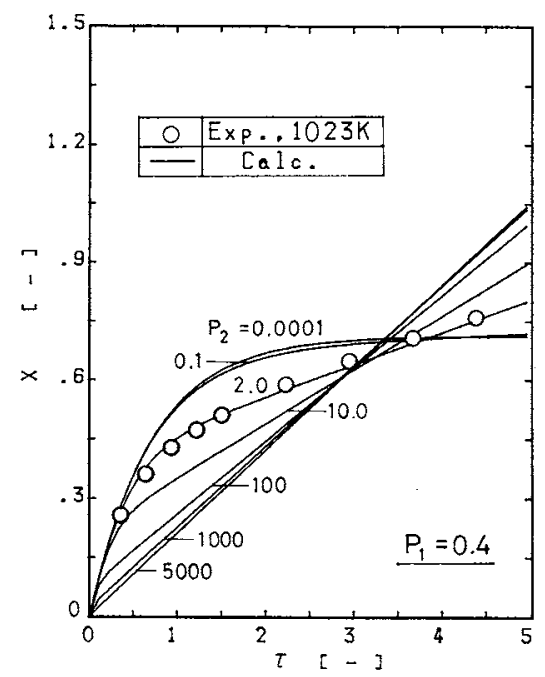

Fig. 11. Effect of $P_{2}$ on calculated reaction rate.

$$
\log \left(k_{1}\right)=-2.78+576 / T
$$

3) Estimation of $k_{1}^{\prime}$ and $k_{2} \quad k_{1}^{\prime}$ and $k_{2}$ were calculated at each temperature from the values of $P_{1}$ and $P_{2}$, which give the most fittable values of $W$ with respect to the experimental data. Figures $\mathbf{1 0}$ and $\mathbf{1 1}$ show the relation between dimensionless deposition weight, $X$, and dimensionless time, $\tau$, using $P_{2}=2.0$ and $P_{1}=0.4$ as fixed parameters, respectively. The

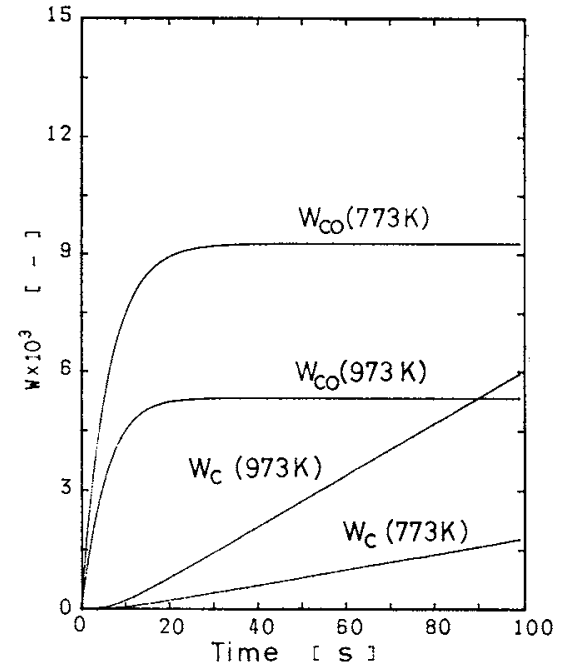

Fig. 12. Calculated weight of deposited carbon and adsorbed $\mathrm{CO}$

plots in these figures represent the experimental data at $1023 \mathrm{~K}$.

\subsection{Comparison of calculated results with experimen- tal ones}

In Fig. 4, the solid lines represent the results calculated from the model discussed above. The relation between $W$ and time is obtained from $X$ and $\tau$ which can be calculated by Eqs. (9)-(11), using the Runge-Kutta-Gill method with the values of the parameters $P_{1}$ and $P_{2}$ which gave the most fittable lines with respect to the experimental data at each temperature. Figure 5 shows a comparison of calculated results with experimental ones at various $\mathrm{CO}$ partial pressures and $973 \mathrm{~K}$. The solid lines are the calculated results on the basis of the present model, using the values of the parameters $P_{1}$ and $P_{2}$ changed as follows:

$$
P_{1}=\left.P_{1}\right|_{P_{\mathrm{CO}}=1} / P_{\mathrm{CO}}, \quad P_{2}=P_{2 \mid P_{\mathrm{CO}}=1} / P_{\mathrm{CO}}
$$

The experimental results agree approximately with the calculated ones. The same results were recognized in all experiments at different reaction temperatures.

Figure 12 shows the calculated weight of adsorbed $\mathrm{CO}, W_{\mathrm{CO}}$, and the weight of deposited carbon, $W_{\mathrm{C}}$, at $773 \mathrm{~K}$ and $973 \mathrm{~K}$. The sum of $W_{\mathrm{CO}}$ and $W_{\mathrm{C}}$ is $W$. It is seen from this figure that the amount of adsorbed $\mathrm{CO}$ at $773 \mathrm{~K}$ is more than that at $973 \mathrm{~K}$, but that the amount of deposited carbon is more at $973 \mathrm{~K}$. The calculated weights of deposited carbon are about 0.5 $(973 \mathrm{~K})$ and $0.15(773 \mathrm{~K})$ at 90 seconds. These values are almost consistent with that of the final weight shown in Fig. 3. Thus, the model in this study gives a possible explanation for the fact that the rate decreases with increasing temperature in the early reaction stage.

Figure 13 shows the Arrhenius plots for $k_{2}$ calculated from the value of $P_{2}$ at each temperature. The 


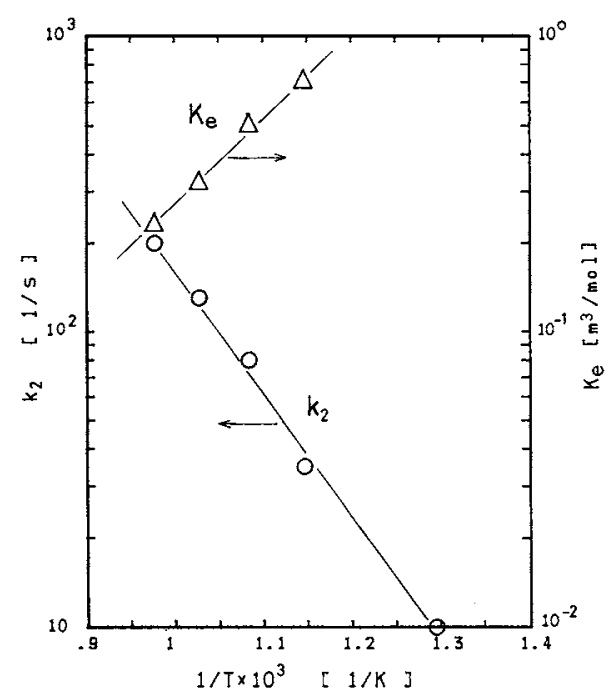

Fig. 13. Arrhenius plots of $k_{2}$ and $K_{e}$.

apparent activation energy is found to be $59.3 \mathrm{~kJ} / \mathrm{mol}$. In the same figure, the relation between $K_{\mathrm{e}}$, calculated from the value of $P_{1}$, and the reciprocal of the absolute temperature is also shown. This relation is linear and the heat of adsorption is obtained as $61.7 \mathrm{~kJ} / \mathrm{mol}$ from the slope of the line. The heat of adsorption of $\mathrm{CO}$ on transition metals lies generally between 55 and $146 \mathrm{~kJ} / \mathrm{mol}^{2)}$ The value obtained in this study also lies in that range.

\section{Conclusion}

The kinetics of carbon deposition was studied. A reaction model composed of adsorption and reaction steps was proposed. This model gives a possible explanation for the maximum rate of carbon deposition at about $773 \mathrm{~K}$. The calculated results on the basis of the present model were in good agreement with the experimental data. The apparent activation energy and the heat of adsorption of $\mathrm{CO}$ was found to be $59.3 \mathrm{~kJ} / \mathrm{mol}$ and $61.7 \mathrm{~kJ} / \mathrm{mol}$, respectively.

\section{Nomenclature}

$C_{\mathrm{CO}} \quad=$ concentration of $\mathrm{CO}$

$K_{e} \quad=$ adsorption equilibrium constant $\quad\left[\mathrm{m}^{3} / \mathrm{mol}\right]$

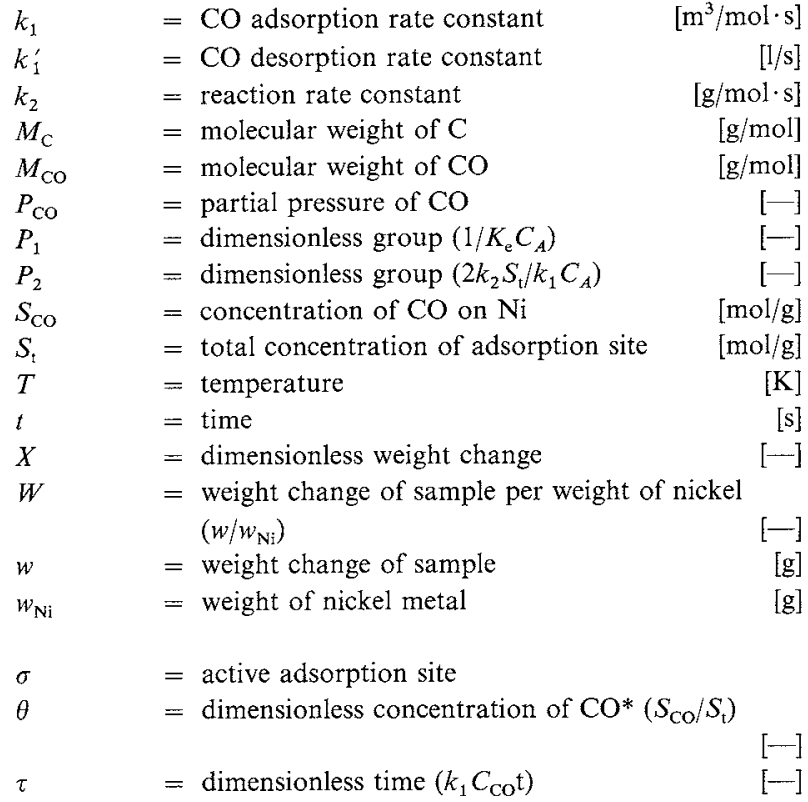

$\langle$ Superscript $\rangle$

* $\quad=$ adsorption state

Literature Cited

1) Audier, M., M. Coulon and L. Bonnetain: Carbon, 17, 391 (1979).

2) Benard, J.: "Adsorption on Metal Surface," p. 91, Elsevier Sci. Pub. Co. (1983).

3) Boehm, H. P.: Carbon, 11, 583 (1973).

4) Knapp, M. R., K. Li and W. O. Philbrook: Met. Trans. B, 6, 513 (1975)

5) Kolesnik, N. F. and G. R. S. Pierre: Met. Trans. B, 11, 285 (1980).

6) Mitsune, G., S. Suzuki, T. Shizuyama and W. Sakai: Kogyo Kagaku Zasshi, 65, 473 (1962).

7) Nielsen, J. R. R.: J. Catalysis, 27, 343 (1972).

8) Nishiyama, Y.: Hyomen, 18, 211 (1980).

9) Olsson, R. G. and E. T. Turkdogan: Met. Trans. B, 5, 21 (1974).

10) Renshaw, G. D., C. Roscoe and P. L. Walker, Jr.: $J$. Catalysis, 18, 164 (1973)

11) Taniguchi, M. and I. Muchi: Tetsu to Hagane, 56, 156 (1970).

12) Taniguchi, M. and I. Muchi: Tetsu to Hagane, 56, 162 (1970).

13) Turkdogan, E. T. and J. V. Vinters: Met. Trans. B, 5, 11 (1974) 